\title{
Una propuesta didáctica para enseñar el ritmo del español a estudiantes de lengua inglesa
}

\author{
María del Pilar Mínguez CALERO \\ Universidad de Alicante \\ mdpm20@alu.ua.es \\ JOSÉ LUIS SIMÓN SARMIENTO \\ Universidad de Alicante \\ jlss5@alu.ua.es
}

\begin{abstract}
Resumen: La enseñanza de la pronunciación en la clase de ELE suele ocupar menos espacio que aquel que se dedica a otros ámbitos lingüísticos, como la gramática o el vocabulario. Tradicionalmente, el acercamiento a la pronunciación ha sido fundamentalmente a través del método fonoarticulatorio (Llisterri, 2003). Se ha hecho hincapié, por ejemplo, en el control consciente de los órganos articulatorios y en la importancia de los sonidos individuales. Nuestra unidad didáctica no niega que algunas de estas técnicas sean útiles en determinados casos, pero reivindica las opciones que ofrece el método verbo-tonal como complemento (Guberina y Murillo, 2008). La unidad didáctica que proponemos tiene como objetivos enseñar conjuntamente el ritmo $\mathrm{y}$ el sonido velar fricativo sordo $[\mathrm{x}]$ a estudiantes de lengua inglesa. Partiendo de algunos principios del método verbo-tonal (Renard y van Vlasselaer, 1976; Poch, 1999; Billières, 2014; etc.), hemos diseñado una secuencia de actividades (Padilla, 2015) que pretende proporcionar a profesores y estudiantes algunas herramientas que contribuyan a la mejora de la pronunciación del español. El uso de la lengua meta, las metáforas visuales y buen humor son algunos de los fundamentos básicos de nuestra propuesta.
\end{abstract}

Palabras clave: ritmo, sonido velar fricativo sordo, verbo-tonal, pronunciación, ELE.

\section{A Didactic Proposal to teach the Rhythm of Spanish to English speaking Students}

Abstract: The teaching of pronunciation in SFL classes tends to be an aspect that is less frequently covered than other linguistic features, such as grammar or vocabulary. Traditionally, pronunciation has been mainly approached through the phono articulatory method (Llisterri, 2003). The conscious control of articulatory organs and the importance of individual sounds have been highlighted. Our didactic unit does not reject the usefulness of these techniques in some cases, but reinforces the options offered by the verbotonal method as a complement (Guberina and Murillo, 2008). The main objective of our didactic unit is to teach together rhythm and the voiceless velar fricative sound to English students. Taking into account some principles of the verbotonal method (Renard y van Vlasselaer, 1976; Poch, 1999; Billières, 2014; etc.), we have designed a sequence of activities (Padilla, 2015) that pretends to provide teachers and students with tools that contribute to the improvement of Spanish pronunciation. The use of the target language, visual metaphors and good humour are some of the basic fundamentals of our proposal.

Key words: rhythm, voiceless velar fricative sound, verbotonal, pronunciation, SFL. 


\section{Plantilla de la Unidad Didáctica}

\begin{tabular}{|c|c|}
\hline NIVEL & B1 (adaptable a otros niveles) \\
\hline OBJETIVOS & $\begin{array}{l}\text { Practicar el ritmo silábico del español } \\
\text { Practicar el sonido }[\mathrm{x}] \\
\text { Fomentar las dimensiones afectiva, productiva y perceptiva. }\end{array}$ \\
\hline $\begin{array}{l}\text { LENGUA } \\
\text { MATERNA DEL } \\
\text { ESTUDIANTE }\end{array}$ & Inglés. \\
\hline CONTENIDOS & Ritmo, sílabas y sonido $[\mathrm{x}]$ \\
\hline DESTINATARIOS & Jóvenes y adultos. \\
\hline DINÁMICA & En grupo. \\
\hline DURACIÓN & 30 minutos (1 sesión) \\
\hline MATERIALES & Powerpoint, fichas con imágenes y buen humor. \\
\hline $\begin{array}{l}\text { ORIENTACIONES } \\
\text { PARA EL } \\
\text { PROFESOR }\end{array}$ & $\begin{array}{l}\text { Las actividades aquí propuestas están diseñadas para alumnos } \\
\text { cuya lengua materna es el inglés, y que por lo tanto tienen } \\
\text { problemas con el ritmo silábico del español. Además, el sonido } \\
{[\mathrm{x}] \text { no existe en su lengua, por lo que es difícil para ellos }} \\
\text { pronunciar ese sonido. Sin embargo, estas actividades pueden } \\
\text { ser aplicadas para cualquier estudiante que empiece a estudiar } \\
\text { la lengua española. }\end{array}$ \\
\hline PARA SABER MÁS & $\begin{array}{l}\text { Gil, J. (2007). Fonética para profesores de español: de la } \\
\text { teoría a la práctica. Madrid: Arco Libros. } \\
\text { Padilla, X.A. (2015). La pronunciación del español. Fonética } \\
\text { y enseñanza de lenguas. Alicante, España: Publicaciones de la } \\
\text { Universitat d'Alacant. }\end{array}$ \\
\hline
\end{tabular}

Figura 1. Unidad didáctica.

\section{El método verbo-tonal}

Probablemente, los profesores de lenguas extranjeras enseñan pronunciación desde tiempos remotos. No obstante, la enseñanza explícita, y reglada, de esta destreza no ha dado lugar a un número muy abundante de métodos. Aunque encontremos una cierta preocupación en algunas escuelas, como la audio-lingual o la comunicativa (Gil, 2007: 126 y ss.), lo cierto es que, quizás, hay dos métodos, ambos dentro del ámbito estructuralista, que destacan por presentar una mayor transcendencia en las aulas: el método fono-articulatorio y el método verbo-tonal. 
El método fonoarticulatorio no es en realidad un método propiamente dicho -en el sentido de una etiqueta aplicable a un conjunto de propuestas unificadas-, sino un conjunto de técnicas, rastreables en algunos métodos o enfoques más generales (Padilla, 2015). Este método -que todavía es muy frecuente en muchos manuales y libros de texto- centra su atención en cómo se articula el sonido y tiene como objetivo que el alumno sea consciente de los órganos que intervienen en la pronunciación de los sonidos. La descripción articulatoria, la repetición, los pares mínimos son técnicas habituales, entre otras, dentro del método.

El método verbo-tonal (MVT), por su parte, tiene técnicas y propuestas claramente establecidas y ha dado lugar a numerosas publicaciones que marcan unas líneas de actuación docente bien definidas. Su creador fue el investigador croata Petar Guberina (Guberina y Murillo, 2008), y, aunque su objetivo inicial era servir de terapia para niños sordos, ha tenido un importante desarrollo en la enseñanza de idiomas (Renard y van Vlasselaer, 1976; Billières, 2014; etc.). Algunos de los fundamentos básicos del MVT son los siguientes: a) la enseñanza de la pronunciación debe comenzar por los rasgos suprasegmentales (entonación, ritmo y acento) y continuar después con los segmentales (sonidos); b) se debe evitar el uso de la escritura durante la clase, centrando la atención en la lengua oral; c) la lengua de instrucción debe ser la lengua meta, en este caso, el español; y d) el buen ambiente en la clase, el humor y el uso de gestos y lenguaje corporal favorece que el alumno desarrolle sus destrezas en el manejo de la lengua extranjera (Poch, 1999; Padilla, 2018; etc.).

\subsection{Secuencia de aprendizaje: seis fases}

Con el fin de que la enseñanza de la pronunciación sea lo más efectiva posible, creemos, siguiendo la propuesta de Padilla (2015: 104-106), que es una buena idea segmentar la secuencia de aprendizaje en una serie de fases.

La primera fase constituye la presentación del modelo. En esta primera fase, el profesor debe mostrar el componente que quiera enseñar a sus alumnos. Por ejemplo, si desea enseñar el ritmo y la diferenciación silábica -como en nuestro caso- lo puede hacer a través de imágenes y utilizando metáforas a las que el alumno puede recurrir posteriormente. De este modo, el alumno está expuesto desde el primer momento a lo que va a aprender a lo largo de la clase. La segunda fase es la percepción mecánica. En esta fase el papel del alumno es escuchar de forma inconsciente el modelo recién mostrado. Conforme a lo anterior el alumno va asimilando el modelo sin ser consciente de ello. La tercera fase es la producción mecánica. En este caso, el alumno repite el modelo de forma automática sin reflexionar sobre los procesos que se llevan a cabo para la producción de ese componente. En la cuarta fase se inician la reflexión y el contraste. Por ejemplo, se pueden llevar a cabo comparaciones con la lengua materna del estudiante o reflexiones sobre las características específicas de la LE. La quinta fase es la percepción consciente. En este caso, el alumno ya conoce el modelo y los ha trabajado de forma inconsciente. Ahora se busca que sea capaz de reconocerlo de forma activa, siendo consciente de lo que está oyendo. En la sexta fase se desarrolla la producción consciente. En este momento es el alumno el que produce siendo consciente del modelo que previamente ha aprendido. Lo hace de forma activa con prácticas controladas por el profesor. Finalmente, la séptima fase se basa en la experimentación, donde el alumno produce de forma libre los componentes aprendidos. 


\section{Procedimiento}

\subsection{Actividad 1. ¡Música, Maestro!}

Para comenzar la actividad, el profesor introducirá la clase hablando de la música y preguntando a los alumnos qué tipos de música les gusta. A continuación, reproducirá tres canciones con diferentes ritmos (Feel the fire, Billie Jean y Young folks) y preguntará a los alumnos cuál les ha gustado más: si las de un ritmo, las de otro; qué tipo de música escuchan; cuál es su artista favorito; etc. Finalmente, el profesor hará ver a los estudiantes que en todas las canciones el ritmo que se ha escuchado es diferente, y que algunas de estas diferencias rítmicas también pueden ser trasladadas a las lenguas. En esta actividad trabajamos la dimensión afectiva.

\subsection{Actividad 2. Introducción y modelo de ritmo}

Una vez se ha introducido lúdicamente el concepto de ritmo, el profesor preguntará a los alumnos sobre cómo lo perciben en español en comparación con su lengua materna: si los españoles hablan muy rápido, muy lento; si les parece una lengua musical o entrecortada; etc. A continuación, mostrará los modelos que se van a usar en clase para representar el ritmo del español y el ritmo del inglés. En nuestro caso, las metáforas de una metralleta para el español, asociada a su ritmo silábico; y un muelle para el inglés, asociado a su ritmo es acentual. Trabajamos la dimensión perceptiva mecánica y afectiva.

\subsection{Actividad 3. Balas y palmas}

Primer paso: el profesor mostrará a sus estudiantes diferentes objetos y su distribución en sílabas relacionadas con la metáfora de la metralleta y las balas. Cada bala representa una sílaba (bala grande $=$ tónica, bala pequeña $=$ átona). El profesor leerá las palabras y explicará la asociación entre sílaba y bala. Cuando lea la palabra, dará una palmada con cada sílaba. Diferenciará asimismo entre sílabas átonas y tónicas, haciéndole ver que las tónicas tienen una mayor importancia y una mayor fuerza en la marcación de dicho ritmo. Cada vez que el profesor lo haga, el alumno deberá repetir el mismo proceso. Con esta actividad estamos trabajando la dimensión perceptiva consciente, ya que los estudiantes se están fijando en un fenómeno fonético concreto; pero también la productiva mecánica, ya que los aprendientes repiten lo que acaban de escuchar, sin pensar o reflexionar en lo que producen.

Segundo paso: a continuación, los alumnos producirán por sí mismos lo que antes se ha hecho como grupo. Aparecerán diferentes objetos junto con las balas que corresponden a cada palabra, es decir, el número de sílabas que contiene y la diferenciación entre tónicas y átonas. El profesor pronunciará la palabra en voz alta; y los estudiantes las producirán haciendo la separación de las sílabas y con palmadas en cada una de ellas. Cuando aparece una sílaba tónica el golpe se hace más fuerte. Trabajamos la dimensión productiva consciente. 


\title{
3.4. Actividad 4. La bruja Maruja
}

El profesor preguntará a los alumnos si recuerdan el personaje de la bruja que ha aparecido en el ejercicio anterior (vid. infra), y leerá un trabalenguas relacionado con ella:

\author{
La bruja maruja prepara un brebaje \\ con cera de abeja, dos dientes de ajo \\ cuarenta lentejas y una pizca de perejil.
}

El trabalenguas contiene el sonido velar fricativo sordo [x], que es el que se va a trabajar a continuación. El profesor pronunciará el trabalenguas con el objetivo de que perciban el modelo que deben aprender.

Concluido esto, preguntará si se saben algún trabalenguas en su lengua y les pedirá que lo compartan con los compañeros; esto favorecerá el ambiente lúdico y les dará confianza para trabajar mejor la pronunciación. Trabajamos la dimensión perceptiva mecánica y afectiva.

\subsection{Actividad 5. ¡Preparados, listos, ya!}

Primer paso: el profesor mostrará una imagen con el diferente vocabulario que se va a trabajar en la actividad. Preguntará si conocen alguno de los objetos que aparecen; y, si no, el profesor los nombrará hasta que se familiaricen con ellos. Algunas de las palabras que utilizadas son: jirafa, jardín, abeja, jinete, jilguero, naranja, árbol, casa, jardinero, jarrón, pájaro, césped, jaula, cielo, sol, nubes, girasol, gimnasta, gemelos, gelatina, genio. etc. Trabajamos la percepción mecánica.

Segundo paso: el profesor pegará en la pizarra, o en la pared, unas tarjetas adhesivas en las que se encontrarán las imágenes que ya han aparecido anteriormente. Las palabras seleccionadas contienen el sonido [x] y la mayoría están combinadas con las vocales [i] y [e] con el propósito de adelantar el sonido para una pronunciación correcta. En este caso, se está utilizando la técnica verbo-tonal de la fonética combinatoria, que explicaremos más adelante. A cada imagen acompañará una segunda tarjeta que contendrá un esquema con las sílabas tónicas y átonas: -'- -, - -', '--.

Tercer paso: el profesor dividirá la clase en dos grupos o más con el mismo número de alumnos. Les pedirá que se levanten y que cada grupo forme una fila enfrente de la pizarra, o la pared, en la que habrá pegado las diferentes tarjetas. Organizará todo según las posibilidades del entorno docente. A continuación, el profesor dirá una de las palabras que aparece en las tarjetas. El primer alumno de la fila de cada grupo deberá ir rápidamente a la pizarra y coger la tarjeta que corresponde a la palabra que el profesor acaba de mencionar. Se la entregará al primer alumno del segundo grupo y este le asociará un esquema silábico (tarjeta 2) a la palabra-imagen elegida (tarjeta 1) por el primer grupo. Si el grupo 2 acierta el esquema, se llevará el punto; si no lo hace, el grupo uno se llevará dos. El número de rondas variará en función del número de palabras y alumnos. Finalmente, el grupo que más puntos obtenga será el ganador del juego. Los tropezones, las carreras, etc. favorecerán un ambiente divertido.

Cuarto paso: una vez los estudiantes se han familiarizado con las imágenes y los esquemas, cada grupo creará cinco enunciados sencillos con los diferentes conjuntos de 
tarjetas. Un alumno del grupo 1 pronunciará el primer enunciado y le pedirá a un alumno del grupo 2 que lo repita. Luego se cambiarán las tornas hasta completar los diez enunciados. El profesor controlará dos cuestiones: a) si cada sílaba se ha pronunciado con la suficiente solidez fónica (es decir, sin relajaciones, diptongaciones, etc.) y b) si los estudiantes han diferenciado correctamente entre tónicas y átonas. Puntuará de 0 a 5 cada una de las actuaciones. Solucionará, por último, las dudas y les recordará a los alumnos las dos actividades iniciales, la de la música y la de los trabalenguas.

En este caso, estamos trabajando las dimensiones perceptiva y productiva conscientes a través de un elemento lúdico y motivador para los estudiantes.

\section{Para el profesor}

En esta unidad didáctica el propósito es enseñar algunos aspectos del ritmo del español a estudiantes angloparlantes en un ambiente divertido y conforme a algunas de las ideas del MVT.

El ritmo puede ser definido como "la sensación perceptiva que producen algunos fenómenos fónicos ... cuando se repiten de forma regular y recurrente" (Padilla, 2015, p. 37). El ritmo, además de ser una sensación perceptiva, está regulado por varios factores, entre ellos, la mayor o menor importancia de unas sílabas sobre otras en la constitución del enunciado. Así, como señala Cantero (2003), puede establecerse que las diferentes sílabas que conforman el enunciado se organizan de forma jerárquica, tomando como punto de partida la mayor relevancia de las sílabas tónicas.

En nuestra unidad didáctica, tenemos como objetivo principal trabajar algunos factores relacionados con las diferencias rítmicas entre el español y el inglés, jugando con dos elementos: a) el reconocimiento de las diferentes sílabas (átonas y tónicas) que componen el enunciado; y b) las diferencias en las tendencias rítmicas: silábica vs. acentual.

En este sentido, el profesor debe contrastar los ritmos del español y del inglés. El inglés, acentual, determina su ritmo por la distancia existente entre los diferentes acentos tónicos de una frase. Esa distancia suele ser más o menos la misma, independientemente de las sílabas que haya entre un acento y otro. Las sílabas a veces se relajan o se diptongan. El español, silábico, marca el ritmo por la duración de las sílabas, que suele ser la misma independientemente de que sean tónicas o átonas. Las sílabas no se relajan, o no lo hacen de forma sistemática. En inglés, por otro lado, existen fenómenos, como el glottal stop, que producen la sensación de un ritmo entrecortado; mientras que las uniones del español, como las sinalefas, provocan que el ritmo del español resulte musical al oído.

Nuestro segundo objetivo es trabajar el sonido velar fricativo sordo [x], y la técnica verbo-tonal utilizada para enseñarlo ha sido la de la fonética combinatoria (Poch, 1999). Dado que el sonido [x] no existe en inglés, los anglohablantes, cuando pronuncian el sonido [x], tienden a aspirarlo. Su punto de articulación está más atrasado que el del español, que es velar. Para conseguir adelantar el punto de articulación de los alumnos anglohablantes, combinamos el sonido $[\mathrm{x}]$ con las vocales $/ i / \mathrm{y} / e /$, es decir, vocales 
anteriores, con el objetivo de que la producción de ese sonido se adelante y, consecuentemente, resulte más sencilla a los estudiantes (Poch, 1999; Padilla, 2018).

\section{Imágenes}

A continuación, mostramos las imágenes que se usarían durante la clase para enseñar el ritmo y el sonido velar fricativo sordo. Consideramos que la forma más adecuada de usar las imágenes es a través de una presentación como puede ser PowerPoint, ya que facilita que las imágenes vayan apareciendo de forma consecutiva.

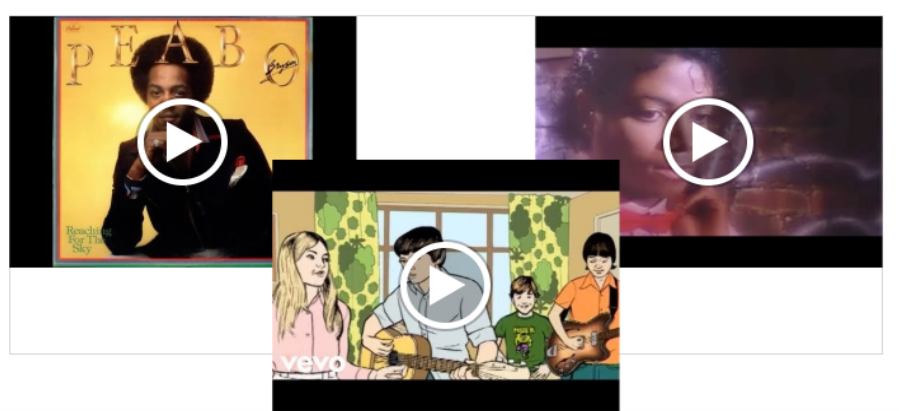

Imagen 1. Presentación de los diferentes ritmos musicales de la actividad 1.
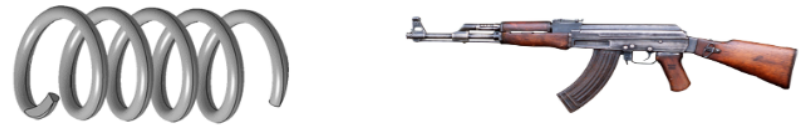

Imagen 2. Presentación del modelo y de las metáforas asociadas al ritmo del español y del inglés.

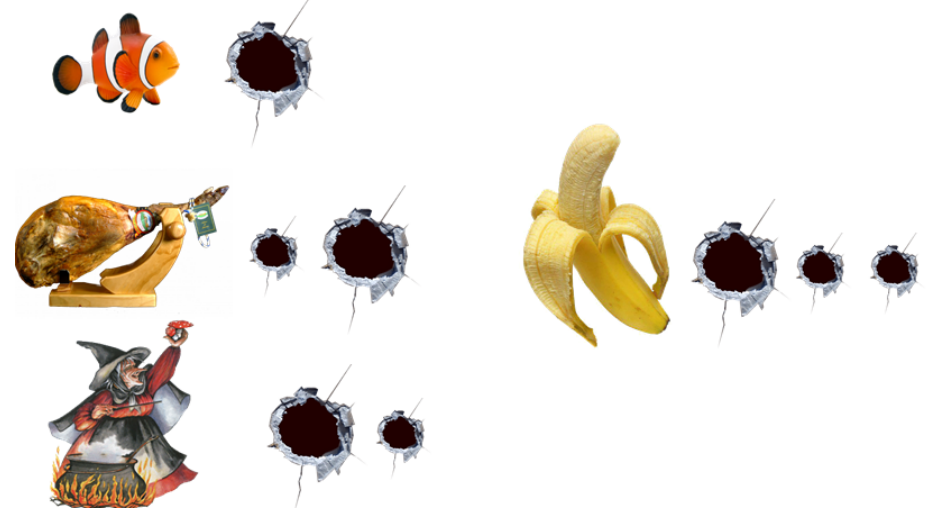

Imagen 3. Presentación de la actividad 3, donde los agujeros de bala están asociados con el número de sílabas de cada palabra. Las palabras que aparecen son "pez”, “jamón”, "bruja” y "plátano”. 

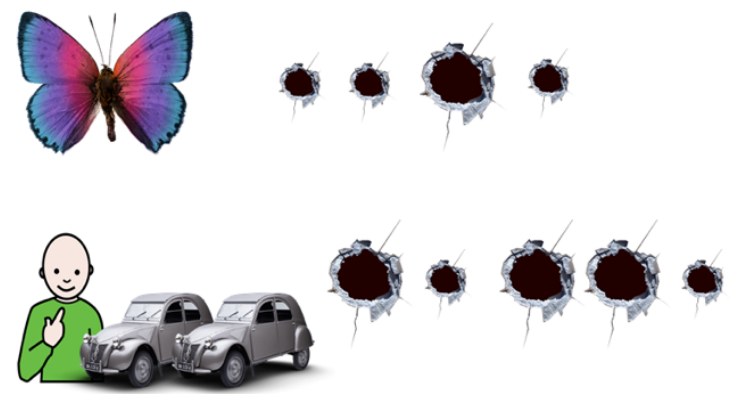

Imagen 4. Continuación de la actividad 3. La palabra y frase que aparecen son "mariposa" y "tengo dos coches".

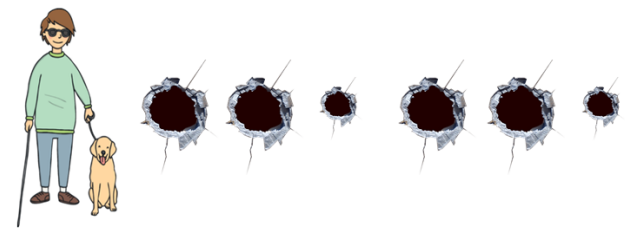

Imagen 5. Continuación de la actividad 3. La frase que aparece es "el perro de Carlos".

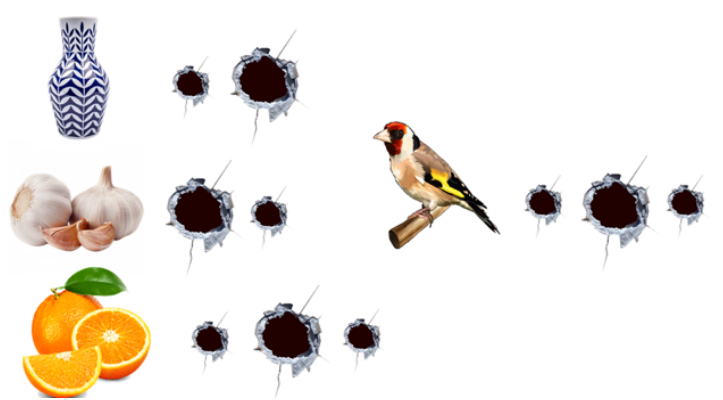

Imagen 6. Segunda parte de la actividad 3. Las palabras que aparecen son "jarrón”, “ajo”, “naranja” y "jilguero".

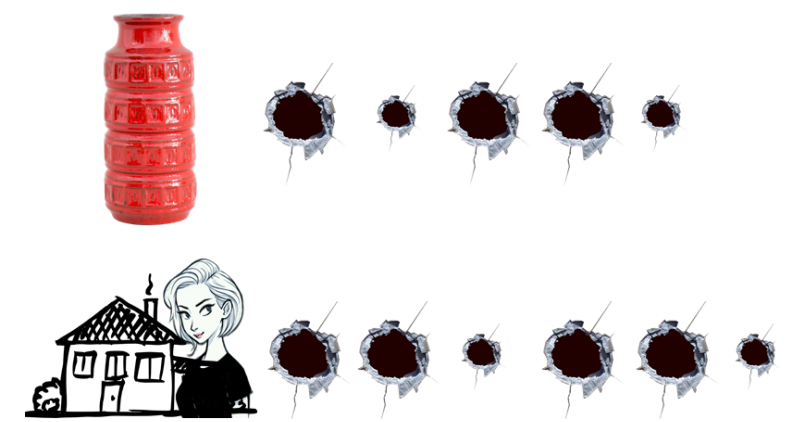

Imagen 7. Continuación de la segunda parte de la actividad 3. Las frases que aparecen son "un jarrón rojo" y "la casa de Julia". 

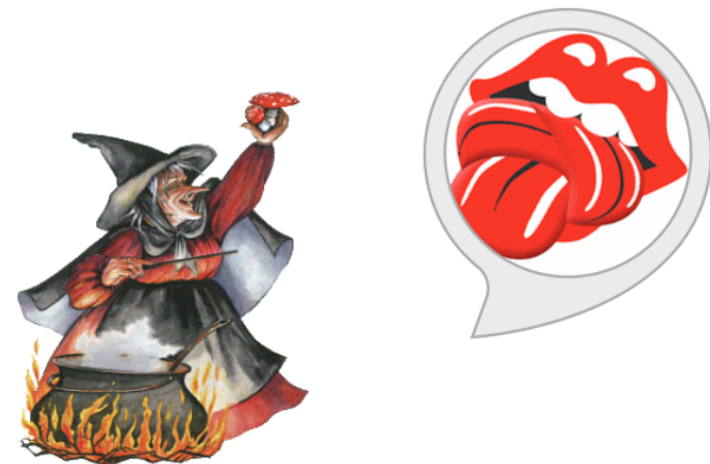

Imagen 8. Introducción de la actividad 4: el trabalenguas de la Bruja Maruja.
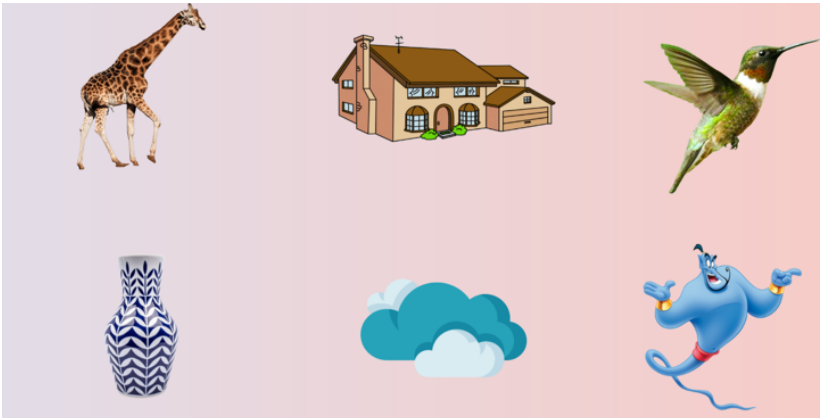

Imagen 9. Primera parte de la actividad 5. Presentación del vocabulario.
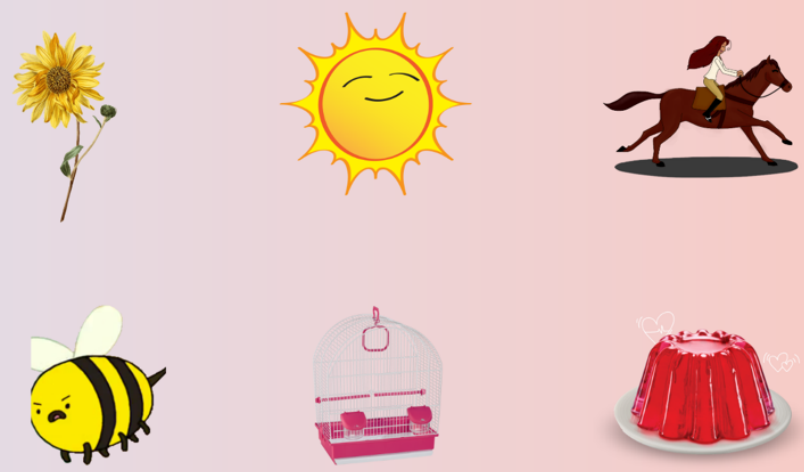

Imagen 10. Continuación de la primera parte de la actividad 5. Presentación de vocabulario.

\section{Tarjetas}

Finalmente, se encuentran las tarjetas con las imágenes que pegaríamos en la pizarra o en la pared. En esta unidad didáctica se presentan doce tarjetas, pero se pueden crear tantas tarjetas como palabras decidamos incluir. 


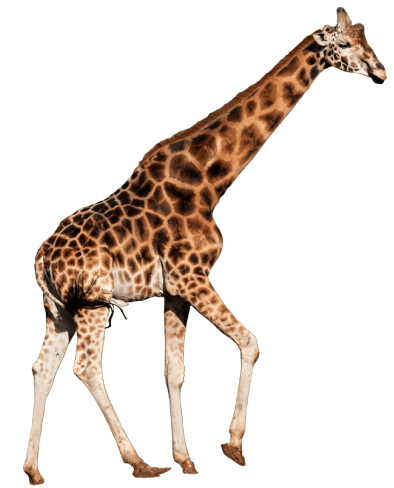

Imagen 11. Tarjeta 1. Palabra "jirafa".

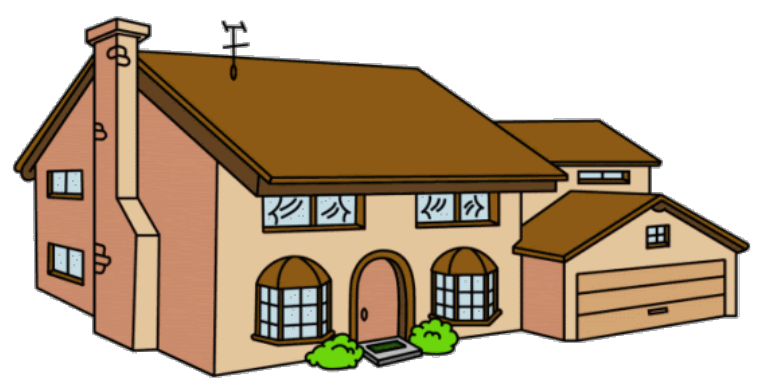

Imagen 12. Tarjeta 2. Palabra "casa".

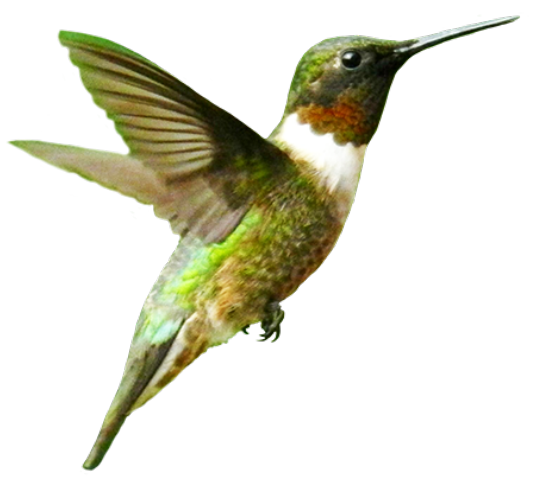

Imagen 13. Tarjeta 3. Palabra "jilguero".

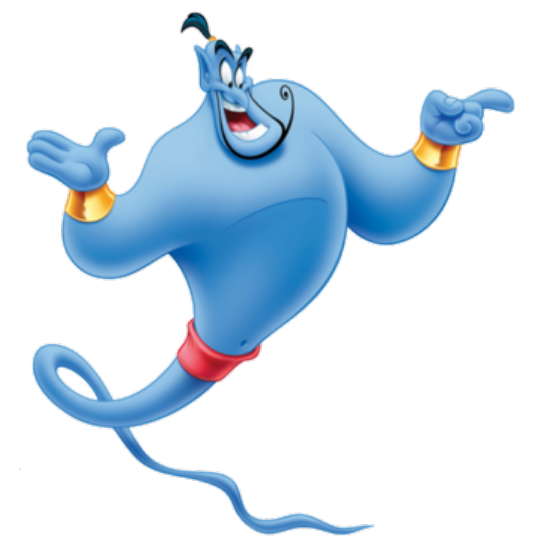

Imagen 14. Tarjeta 4. Palabra "genio". 


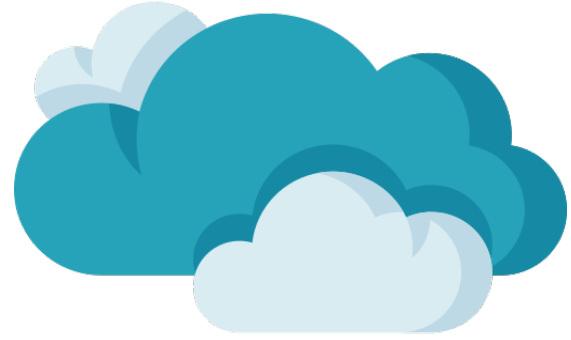

Imagen 15. Tarjeta 5. Palabra "nubes".

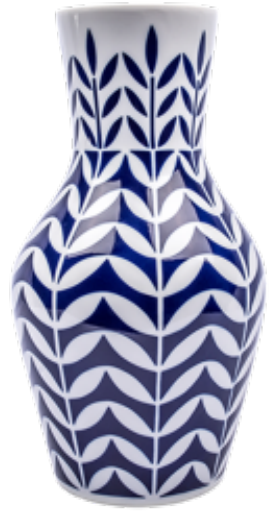

Imagen 16. Tarjeta 6. Palabra "jarrón"

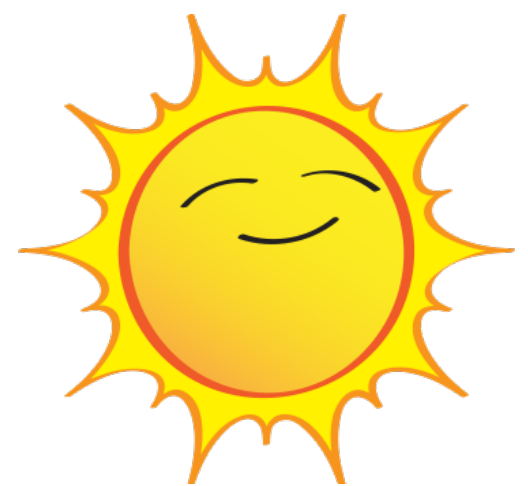

Imagen 17. Palabra 7. Palabra "sol".

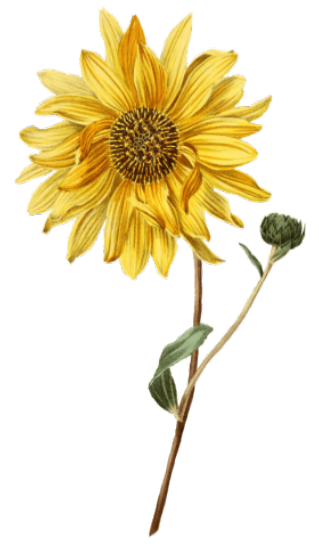

Imagen 18. Tarjeta 8. Palabra "girasol". 


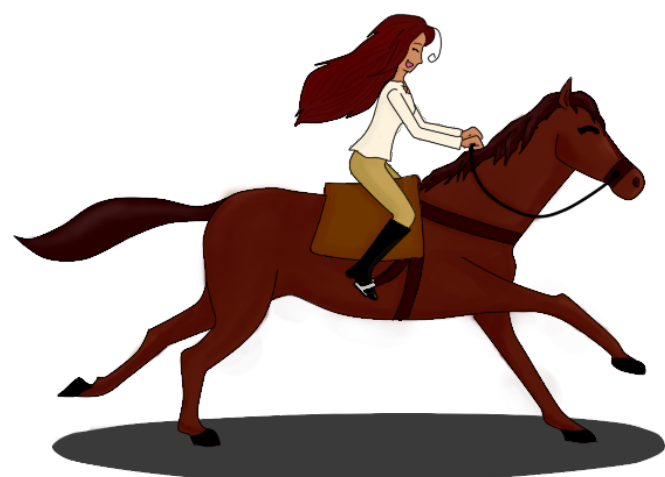

Imagen 19. Tarjeta 9. Palabra "jinete".

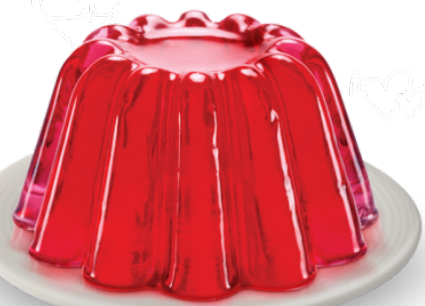

Imagen 20. Tarjeta 10. Palabra "gelatina".

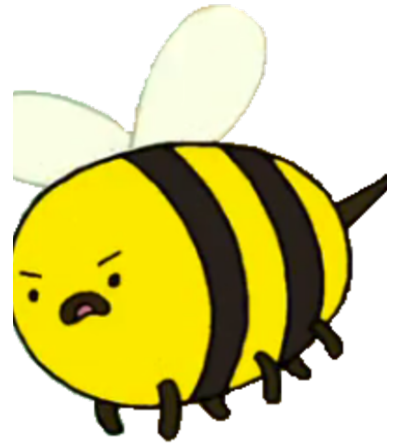

Imagen 21. Tarjeta 11. Palabra “abeja”.

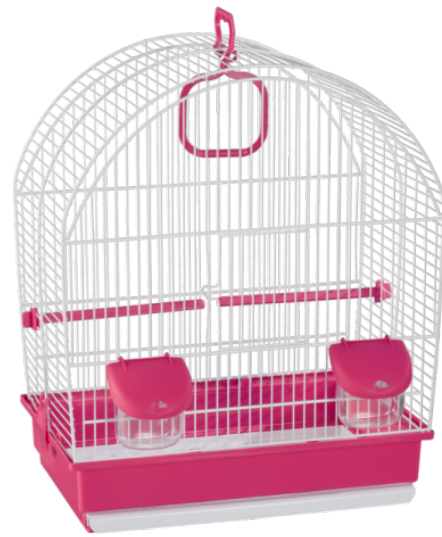

Imagen 22. Tarjeta 12. Palabra "jaula". 
Imagen 23. Tarjeta 13. Esquema de sílabas tónica y átonas 1.

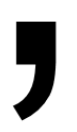

Imagen 24. Tarjeta 14. Esquema de sílabas tónica y átonas 2.

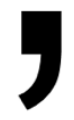

Imagen 25. Tarjeta 15. Esquema de sílabas tónica y átonas 3.
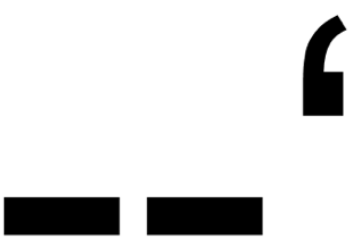

Imagen 26. Tarjeta 16. Esquema de sílabas tónica y átonas 4. 


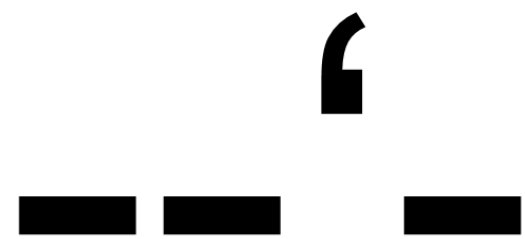

Imagen 27. Tarjeta 17. Esquema de sílabas tónica y átonas 5.

\section{Bibliografía}

BILliÈRES, M. (2014). «VADE-MECUM de phonétique corrective à l'usage des professeurs de FLE». Recuperado de: https://www.verbotonale-phonetique.com/wpcontent/uploads/2014/11/vade-mecum.pptx.compressed.pdf.

CANTERo SERENA, F.J. (2003). «Fonética y didáctica de la pronunciación». En A. Mendoza (coord.), Didáctica de la Lengua y la Literatura para Primaria (pp. 545-572). Madrid: Pearson/Prentice Hall.

GIL Fernández, J. (2007). Fonética para profesores de español: de la teoría a la práctica. Madrid: Arco Libros.

GuberinA, P. y MuRILlo, J. (2008). Retrospección (traducción y prólogo de Julio Murillo). Mons: CIPA.

Instituto Cervantes. Centro Virtual Cervantes. Didactiteca. España. Recuperado de: https://cvc.cervantes.es/aula/didactired/didactiteca/

LlisterRI, J. (2003). «La enseñanza de la pronunciación», Revista del Instituto Cervantes en Italia, 4, 1, pp. 91-114.

Padilla García, X.A. (2015). La pronunciación del español. Fonética y enseñanza de lenguas. Alicante: Publicaciones de la Universitat d'Alacant.

PADILLA GARCÍA, X.A. (2018). «Remarks on verbo-tonal phonetics for a communicative context», Normas, 8, pp. 259-271. doi: https://doi.org/10.7203/Normas.v8i1.13433

Poch, D. (1999). Fonética para aprender español: pronunciación. Madrid: Edinumen.

ReNARD, R. y VAN Vlasselaer, J.J. (1976). Foreign Language Teaching with an Integrated Methodology: the SGAV (Structuro-Global Audio-Visual) Methodology. Paris: Didier. 